ARTIGO ORIGINAL

\title{
A aula de educação física no ensino médio: um panorama da participação dos alunos da região da Grande Dourados - MS
}

The lecture of physical education in middle school: a panorama of the participation of students in the region of Grande Dourados - MS - Brazil

Crislaine Amelia de Souza, Josiane Fujisawa Filus de Freitas, Cássia Cristina Furlan

Universidade Federal da Grande Dourados (UFGD), Dourados/MS, Brasil

\section{HISTÓRICO DO ARTIGO}

Recebido: 24 maio 2020

Revisado: 27 outubro 2020

Aprovado: 03 novembro 2020

\section{PALAVRAS-CHAVE:}

Educação Física; Ensino Médio; Qualidade de vida.

\section{KEYWORDS:}

Physical Education; High school; Quality of life.

\section{RESUMO}

OBJETIVO: O objetivo desta pesquisa foi apresentar a percepção dos alunos do Ensino Médio sobre as aulas de Educação Física (EF).

MÉTODOS: Este estudo é de natureza qualitativa do tipo descritiva, participaram 452 alunos regulamente matriculados no ensino médio de 5 escolas da rede pública da região de Dourados (MS). O questionário utilizado foi criado por Darido (2004) e adaptado pelos autores, continha 17 questões e foi aplicado em formulário online.

RESULTADOS: Constatou-se que os alunos do Ensino Médio participantes da pesquisa tem uma opinião positiva sobre a disciplina e participam das aulas, no entanto, não a consideram relevante para seu aprendizado. Verificou-se também que muitos alunos não praticam atividades físicas fora da escola.

CONCLUSÃO: Concluiu-se que há a necessidade de promover maior envolvimento de professores e alunos para o reconhecimento da importância da disciplina EF a fim de que ela, a partir da escola, ofereça diversificação de conteúdos e motivação para a prática, auxiliando também na conscientização da importância de uma vida ativa (aliada a outros fatores) para uma boa qualidade de vida.

\section{ABSTRACT}

OBJECTIVE: The objective of this research was present the perception of high school students about Physical Education classes.

METHODS: This study is qualitative in the descriptive type, attended by 452 students enrolled in the high school of 5 public schools in the region of Dourados (MS). The questionnaire used was created by Darido (2004) and adapted by the authors, contained 17 questions and was applied in an online form.

RESULTS: It was found that the high school students participating in the research have a positive opinion about the discipline and participate in the classes, however, they do not consider it relevant to their learning, it was also verified that many students do not practice physical activities outside the school.

CONCLUSION: It was concluded that there is a need to promote greater involvement of teachers and students in the recognition of the importance of the Physical Education discipline so that it, from the school, offers diversification of contents and motivation for practice, also helping to raise awareness of the importance of an active life (combined with other factors) for a good quality of life. 


\section{INTRODUÇÃO}

A área da Educação Física (EF) contempla múltiplos conhecimentos produzidos e usufruídos pela sociedade a respeito do corpo e do movimento. Na escola, como um campo de conhecimento que trabalha com a cultura corporal de movimento, tem como objetivo formar um indivíduo que possa recriar, reproduzir e apreciar criticamente tais práticas vivenciadas no ambiente escolar levando-as para o seu cotidiano (BRASIL, 2000) e, especialmente no Ensino Médio, priorizar a fruição e análise das linguagens de maneira crítica, levando alunos e alunas a um aprofundamento das experiências e percepções vivenciadas nos anos anteriores de escolarização (BRASIL, 2018).

Historicamente, a Educação Física serviu a funções específicas, como a formação de mão de obra ao mercado (BRACHT, 2010) - e, ao longo de sua estruturação, várias críticas foram sendo feitas com relação ao seu desempenho na escola e também ao dos próprios professores. Foi a partir dos anos 1980, principalmente, que marcou-se um período de crise da EF, quando diversas pesquisas e livros foram sendo publicados a fim de estudar tais características predominantes na área e modificá-las no sentido de produzir uma Educação Física que congregasse funções de formação integral, crítica e autônoma com o objetivo de que a aproximassem da realidade do seu encargo educacional (BRASIL, 2000). Assim, como salientado por Wanderley Jr. e Cezar (2013), a EF não prepara especificamente para o vestibular ou mercado de trabalho, mas sim para a vida em prol do desempenho crítico, da cidadania e da melhoria da qualidade de vida.

Nesse interim, o objetivo principal da Educação Física escolar é ensinar e inserir o aluno no universo da cultura corporal de movimento. Conforme Darido (2004), o dever da EF na escola é fornecer requisitos para que alunos e alunas analisem criticamente os aspectos inerentes às diferentes manifestações da cultura corporal e conquistem autonomia em relação à prática regular de atividades físicas vivenciadas no ambiente escolar para recriá-las fora desse espaço formal, durante e após a escolaridade, com ou sem auxílio de especialistas. A autora afirma que se os alunos tiverem prazer durante a realização das aulas de educação física, identificando-se com alguma atividade, é provável que almejem continuá-la e recriá-la após sua formação na educação básica.

Algumas pesquisas apontam que a Educação Física tem propiciado satisfação à grande parcela dos alunos (BRANDOLIN et. al., 2015; DAMASCENO et al., 2016). No entanto, em diversas escolas é evidente a não participação deles nas aulas, sendo imprescindível a compreensão da importância da EF para esses alunos, conforme Melo (2013). Por esse ângulo, a evasão cresce quando chegam ao Ensino Médio, fase em que, como se constatam em outros estudos (RIPARI et. al, 2018; FARIAS et. al, 2017; CARDOSO. NUNEZ, 2014; FERREIRA et al., 2014; WANDERLEY JR.; CEZAR, 2013; TEIXEIRA; FOLLE, 2011), acaba por se tornar um espaço de repetição de conteúdos já trabalhados ao longo de toda a escolarização fundamental e/ou mesmo de valorização excessiva dos esportes tradicionais, limitando as experiências discentes. Portanto, é preciso dedicação à construção e estruturação do planejamento - como em todas as outras etapas do ensino - para que se priorize a diversificação e complexi- ficação dos conteúdos, buscando a manutenção da motivação e interesse de alunos e alunas (MELO, 2013), além da garantia de um trabalho efetivo que proporcione, desde cedo, a consciência acerca da importância da atividade física, para além dos muros da escola.

Todos esses aspectos corroboram com o fato de que a EF precisa constituir-se enquanto um campo de conhecimentos e experiências que agregue interesses, expectativas e necessidades dos estudantes e da sociedade visto que, como salientado por documentos norteadores do seu trabalho pedagógico, a exemplo dos Parâmetros Curriculares Nacionais (PCNs) (BRASIL, 2000) e a BNCC (BRASIL, 2018), a EF no ensino médio tem suas próprias características, devendo levar em consideração as experiências vivenciadas pelos estudantes nos níveis de ensino anteriores, as novas propostas de ensino e a nova cara que se almeja para a disciplina com relação à formação desses indivíduos nessa fase final do ensino básico, ampliando e criando oportunidades para que os mesmos compreendam as inter-relações entre os saberes, as práticas corporais e os diferentes campos da atividade humana.

Partindo desse contexto, o presente estudo buscou apresentar a percepção que os alunos do Ensino Médio têm sobre as aulas de $\mathrm{EF}$, a fim de compreender os fatores presentes no envolvimento e participação deles neste ciclo de ensino, e estabelecer relações entre ela (EF) e a prática de atividades físicas fora do âmbito escolar.

\section{MÉTODOS}

Trata-se de uma pesquisa de natureza quanti-qualitativa do tipo descritiva, em que as opiniões dos alunos a respeito da disciplina de Educação Física foram registradas, analisadas, classificadas e interpretadas (ANDRADE, 2010), a fim de descrever as características da experiência das aulas e proporcionar novas reflexões sobre a realidade já conhecida.

Este estudo foi realizado em 5 escolas da rede pública de ensino da região da Grande Dourados-MS. Todas as escolas de ensino médio da cidade (total 19) foram contactadas e cinco delas deram permissão para a realização da pesquisa, uma da região central da cidade, duas de bairros próximos ao centro e duas escolas de bairros periféricos.

Foi aplicado questionário para 452 alunos regulamente matriculados no $3^{\circ}$ ano do Ensino Médio, período matutino e vespertino. O questionário utilizado foi criado por Darido (2004) e adaptado para essa pesquisa, continha 14 questões fechadas e uma aberta. As questões abordaram os seguintes temas: a) preferências pelas disciplinas escolares; b) a importância das disciplinas dentro do currículo escolar; c) a participação dos alunos nas aulas de EF; e d) a prática de atividade física fora da escolar.

Os dados foram coletados no ano de 2017 e 2018, pelo Grupo de Pesquisa em Educação Física Escolar e Saúde (UFGD). O questionário foi aplicado pelos acadêmicos do curso de Educação Física, integrantes do grupo de pesquisa (os quais receberam treinamento sobre a aplicação do mesmo). As direções das escolas foram contatadas pelos pesquisadores, os quais formalizaram o pedido em documento escrito e após a aprovação do gestor escolar, o questionário foi aplicado aos alunos que entregaram o Termo de Consentimento Livre e Esclarecido (TCLE) assinado pelo responsável. 
As etapas da coleta de dados estão listadas a seguir: a) Contato com diretor da escola e autorização para realização da pesquisa; b) Organização com professor de EF para utilização da aula e da sala de informática da escola para aplicação do questionário online; c) Explicação para os alunos sobre a pesquisa e entrega do TCLE; d) Aplicação do questionário online durante a aula de EF aos alunos que trouxeram o TCLE assinado; e) Em duas escolas foi utilizado o questionário impresso devido à dificuldade para acessar o formulário online;

A pesquisa foi aprovada pelo Comitê de Ética em Pesquisa (CAAE 55289916.4.0000.5160). A tabulação e análise dos dados foram realizadas no software Excel for Windows ${ }^{\circledR}$, versão 2010, que permitiu análise estatística descritiva e cálculos estatísticos de percentis.

\section{RESULTADOS}

A Figura 1 apresenta dados relativos à participação dos alunos nas aulas de EF. Verificou-se que $62,61 \%$ dos alunos citaram participar das aulas, ou seja, realizam as atividades propostas, não ficam sentados ou fazendo outra atividade que não seja aquela programada pelo professor. Embora seja a maioria, esse valor não pode ser considerado uma porcentagem positiva, visto que se trata de uma disciplina obrigatória do currículo escolar, e uma porcentagem significativa de alunos $(30,31 \%)$ informaram participar "às vezes" da aula, ou nunca participar (7,08\%).

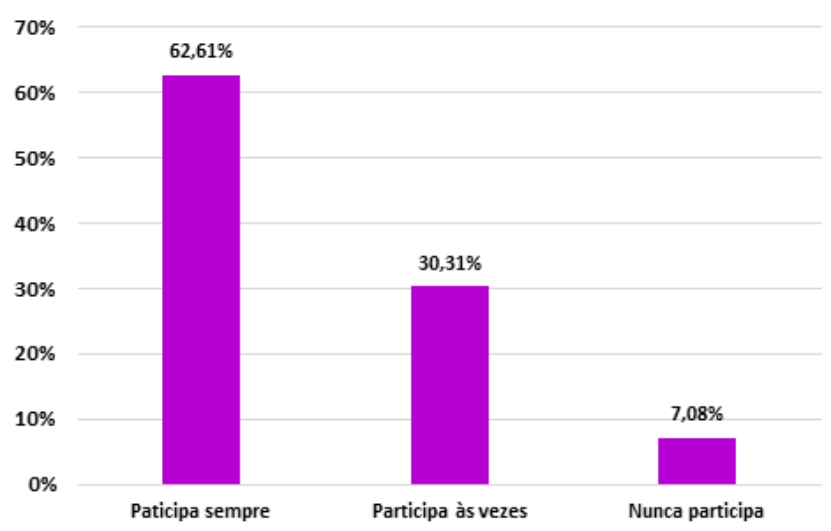

Figura 1. Valores percentuais sobre a participação dos alunos nas aulas de educação física. Fonte: os autores.

Para Cardoso e Nunez (2014), esse fato pode ser resultado da falta de planejamento dos professores na elaboração de aulas que em muitos casos desconsideram a relevância social dos conteúdos segundo o contexto dos estudantes. Assim, muitas vivências acabam se restringindo à prática descontextualizada da realidade, ou seja, a prática pela prática, cerceando a possibilidade de os estudantes vivenciarem diversos elementos da cultura corporal de movimento.

Corroborando com essa análise, alguns estudos (FARIA et al., 2017; CORDOVIL et al., 2015; MELO, 2013; SOUZA; PAGANI, 2012; WANDERLEY JR.; CEZAR, 2013) citam que o conteúdo predominante na aula é o Esporte e sabe-se que, em muitas ocasiões não é uma aula ministrada com sequência pedagógica de fundamentos ou tática esportiva, mas sim voltada à recreação, um momento descompromissado.

Brandolin et al. (2015) realizaram um estudo com alunos do Ensino Médio da rede pública com o objetivo de entender quais elementos se integravam a satisfação nas aulas de EF. O estudo constatou que os alunos com mais habilidades têm sete vezes mais chances de ficarem satisfeitos com as aulas de EF do que os menos habilidosos, além disso, os que fazem atividades físicas fora do contexto escolar tem um e meio mais chances de ficarem satisfeitos com as aulas que os que não praticam. Considerando-se as questões de gênero, os meninos têm três vezes mais chances de ficarem satisfeitos com as aulas do que as meninas.

Entre os motivos para participar das aulas as respostas mais citadas foram: divertimento $(30,31 \%)$, e ganhar nota $(26,55 \%)$, sendo o último um dado preocupante, pois um grande percentual de alunos participa das aulas somente com interesse em obter nota.

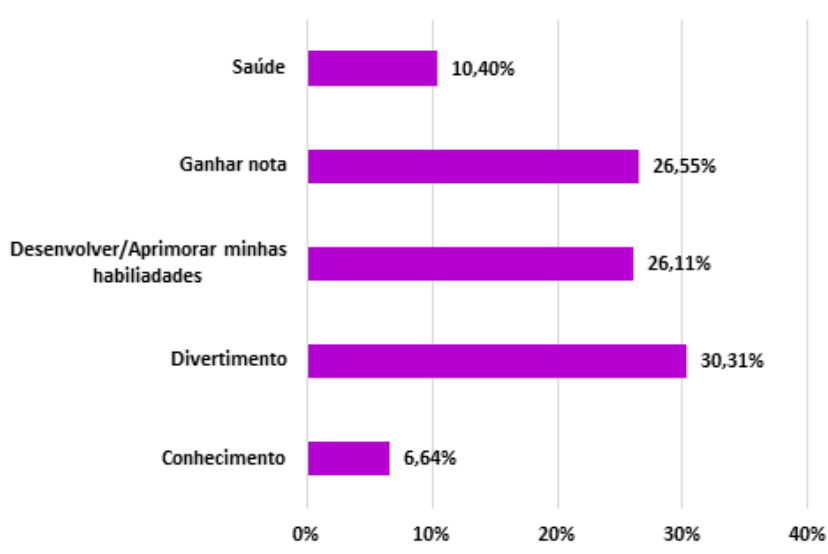

Figura 2. Valores percentuais sobre os motivos que fazem os alunos participarem das aulas. Fonte: os autores.

Provavelmente, esse motivo também possa ser o incentivador de outras disciplinas escolares, porém analisando a disciplina de Educação Física pode-se levantar algumas hipóteses para esse dado como, por exemplo, um descaso em relação à disciplina, ou mesmo, um desconhecimento em relação à importância da EF.

Cardoso e Nunez (2014), verificaram em seu estudo que a "preguiça" e a falta de habilidade foram os motivos mais citados pelos alunos. Um dado que também preocupa é que $16,5 \%$ dos alunos e alunas se consideram desmotivados nas aulas, que os instigam a não participarem das mesmas.

Em pesquisa realizada por Damasceno et al. (2016), com 974 alunos do 7ㅇ e 9o ano do Ensino Fundamental anos finais de escolas públicas e particulares da Região Metropolitana de Campinas (SP), buscando verificar a motivação que os estudantes possuem ao participarem das aulas de EF, constatou-se que os alunos consideram a disciplina como sua favorita, sentem-se bem durante as aulas estando motivados de forma tanto intrínseca quanto extrínseca, mas não a consideram com um grau de importância elevado, se comparado aos demais componentes curriculares. 
Acreditamos que um dos fatores para esse contexto seja resultado de uma prática docente aligeirada e/ou descompromissada. Mesmo não sendo o foco do trabalho discutir os motivos que levam professores e professoras à essa prática, é importante que se compreenda também que tal descompromisso deve ser analisado a partir de uma série de elementos que constituem essa realidade, tais como o descontentamento com suas condições de trabalho - muitas vezes exaustivas - com a qualidade do ensino, com as relações de trabalho, a desvalorização social, violência escolar e também com a remuneração baixa do salário, entre outros.

No entanto, se analisarmos os resultados da questão relacionada à disciplina que alunos e alunas mais gostam, verificamos que a Educação Física é a mais citada, como demonstra a Figura 3.

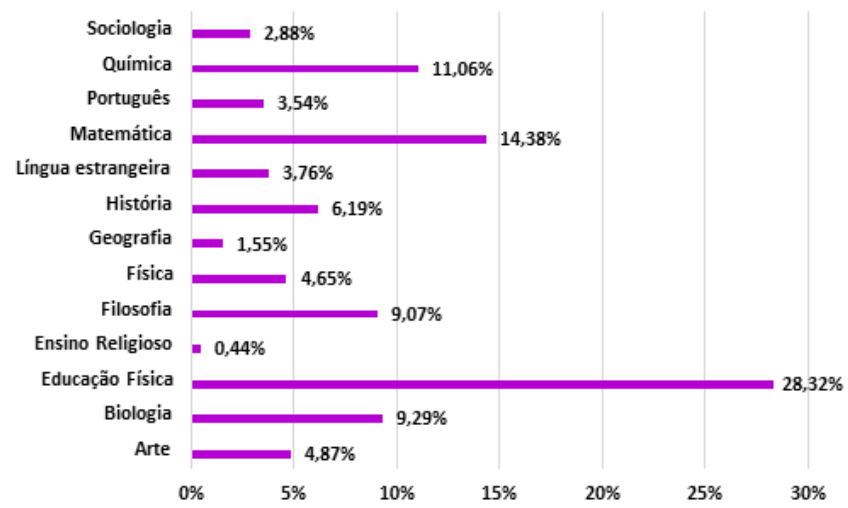

Figura 3. Valores percentuais sobre as disciplinas que os alunos mais gostam. Fonte: os autores.

Entre as disciplinas que os alunos pesquisados mais gostam, EF foi a mais votada com $28,32 \%$, seguida de Matemática $14,38 \%$ e Química com $11,06 \%$. A preferência por EF pode estar relacionada com a saída de um local que é mais monótono para um mais dinâmico e entusiasmante que permite maior socialização entre alunos e alunas. Além disso, algumas outras características da prática cotidiana (nem sempre positivas para a área) podem contribuir também para essa preferência: pelo fato de os professores não transmitirem conteúdos e nem cobrarem tais conteúdos (numa dimensão de sala de aula); pelos alunos acharem que é um componente curricular que não reprova ou que não tem peso em um vestibular ou no Exame Nacional do Ensino Médio (ENEM).

De acordo com os estudos de Brandolin et. al. (2015) e Damasceno, Freitas e Leonardi (2016), foi analisado que a EF é a disciplina que mais provoca satisfação para grande parcela dos alunos, mas numa escala de importância, ela não parece entre as primeiras escolhas. Isto significa que a EF é uma disciplina que está ligada à prática corporal de movimento, provoca um nível de satisfação alto na maioria dos alunos, porém, é comum ser considerada como uma disciplina complementar e com grau de importância inferior.

Para Wanderley Jr. e Cezar (2013), a EF aparenta não ter uma identidade legitimada a partir de um conhecimento válido no conjunto escolar, e percebe-se, tanto na comunidade escolar como fora dela, mas principalmente entre os gestores escolares, que a EF, como uma disciplina caracterizada por trabalhar com o corpo e não com o intelecto, não é valorizada como tendo fundamentos característicos de importância para a formação do estudante.

Esse fato é verificado quando analisamos as respostas dos pesquisados sobre as disciplinas consideradas mais importantes, constatando-se que a EF não ocupa o primeiro lugar (Figura 4).

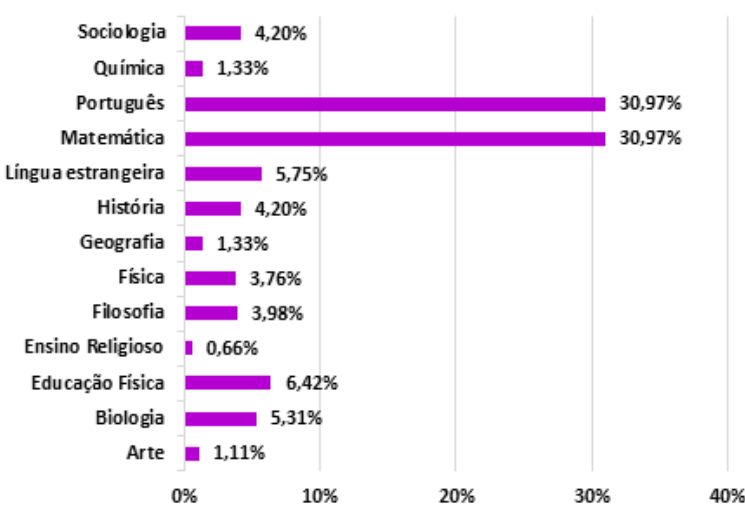

Figura 4. Valores percentuais sobre as disciplinas que os alunos acham mais importantes. Fonte: os autores.

Dentre as disciplinas consideradas mais importantes, a Educação Física ocupa o terceiro lugar com 6,42\%, abaixo de Português e Matemática com respectivamente $30,97 \%$ das escolhas. $O$ dado indica que os estudantes classificam a EF com um grau de importância considerável, mas não o suficiente para a participação efetiva nas aulas.

Porém, percebe-se que os alunos pesquisados gostam da disciplina pelo divertimento que esta proporciona e, portanto, não a consideram fundamental em sua formação, talvez pela forma como é ministrada nas escolas ou pelo ambiente de descontração e pouca exigência que apresenta quando comparada às demais disciplinas e sua importância no exame vestibular, conforme explicitam Wanderley Jr. e Cezar (2013).

Cordovil et al. (2015, p. 842), explicitam que o fato de os alunos não conhecerem o real significado das aulas de EF pode ter relação com a falta de importância que eles atribuem para a disciplina no Ensino Médio. Isso talvez possa justificar a não participação dos mesmos nas aulas. Porque se o aluno não vê importância em alguma coisa também não há o ato de se comprometer com aquilo. Os autores implicam que isso parte da atuação "falha" e/ou desinteressada dos professores, estando "ali como figura simbólica apenas para acompanhar os alunos", o que não consolida e muito menos corrobora com a valorização da Educação Física no Ensino Médio.

Melo (2013) explica que para entender a EF como disciplina do currículo escolar, é essencial compreender a importância que ela dispõe na vida dos adolescentes. Sua pesquisa foi realizada com a finalidade de constatar quais os principais motivos que fomentam a evasão dos estudantes nas aulas de EF no ensino médio. A pesquisa verificou que entre os motivos elencados podem ser citados as repetições dos conteúdos trabalhados no 
Ensino Fundamental, dificuldades financeiras que algumas famílias encaram, e a carência de habilidades corporais necessárias à prática de alguns conteúdos.

Sobre este último motivo, os conteúdos abordados não são focados na diversidade dos elementos da cultura corporal de movimento, mas se restringem aos esportes tradicionais "quarteto mágico" (BRACHT, 2010) - ocasionando, pouca variedade de conteúdos/conhecimentos, o que contribui para o desinteresse e a evasão na disciplina.

Apesar da abrangência de conteúdos que a EF pode abarcar é possível verificar a predominância do conteúdo esporte nas aulas (Figura 5).

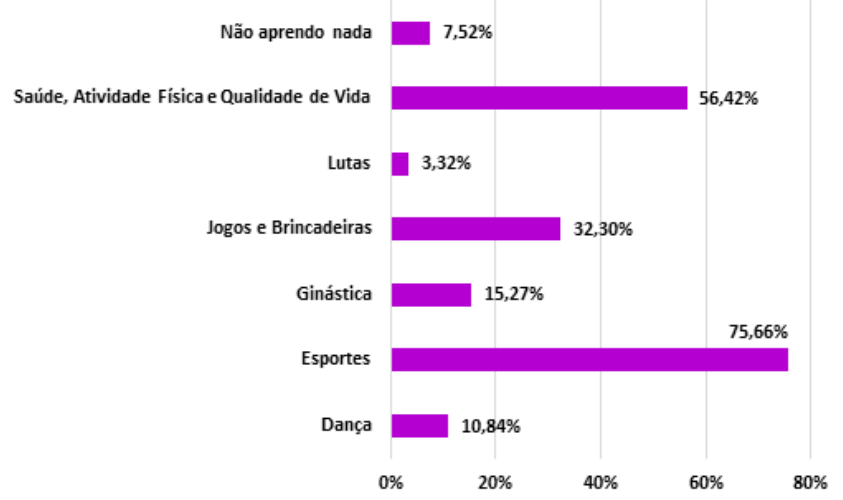

Figura 5. Valores percentuais sobre os conteúdos mais aprendidos nas aulas, segundo os alunos. Fonte: os autores.

Sobre os conteúdos mais aprendidos pelos alunos nas aulas estão: esportes (75,66\%); saúde, atividade física e qualidade de vida com (56,42\%); e jogos e brincadeiras (32,3\%). Pode-se analisar que não existe uma variedade de conteúdos oferecida aos alunos, tendo um percentual elevado do conteúdo "esporte".

Coadunando com os dados apresentados, Farias et al. (2017) e Cordovil et al. (2015), também verificaram que o conteúdo esporte predomina na EF escolar, muitas vezes reafirmando uma suposta hegemonia esportiva, deixando em segundo plano as diversas possibilidades que podem ser exploradas nas aulas de EF.

Sobre essa predominância do conteúdo "esportes" nas aulas de EF, Farias et. al. (2017) argumentam ser necessário uma formação continuada mais profunda que capacite os professores para lidarem com os conteúdos da cultura corporal de movimento, com os quais não tem afinidade ou mesmo pouco conhecimento, como dança, ginástica e lutas.

Além destes dados, Farias et al. (2017) apontam um dado importante: quanto maior for a importância dada ao condicionamento físico e à prática esportiva pelo estudante fora do ambiente escolar, menor destaque é atribuído à obrigatoriedade da prática dessa disciplina dentro das escolas, visto que há vivência e valorização de tais práticas em outros espaços. $O$ autor ressalta que o conhecimento fora da escola é resultante, em grande medida, do que se percebe e se aprende dentro dela, fruto da atuação do professor de Educação Física e dos conceitos e valores que perpassam a área.
Para Cardoso e Nunez (2014), os professores precisam elaborar aulas com conteúdos que façam parte do contexto dos estudantes, para que vivenciem muitas outras coisas e não só a prática pela prática, considerando a individualidade de cada um. Para além do olhar a partir dos estudantes, também é necessário considerar os desafios à prática docente e a atuação do professor nos espaços de educação formal.

Santos et al. (2014) apontam para a necessidade de valorização das narrativas docentes e discentes no processo de escolarização, salientando que tanto no campo de formação de professores quanto no campo do currículo e práticas pedagógicas existe um entendimento voltado para a valorização das experiências e da narrativa docente produzindo protagonismo na produção de conhecimentos por parte do professor. Por meio das apreciações e da análise das experiências da sua atuação no processo de ensino aprendizagem, promovem-se ações que possibilitam um processo de "investigação-formação" através de um método auto formativo, permitindo que o professor expresse suas várias maneiras de trabalhar em conjunto com a escola e, assim, possa encontrar na sua atuação profissional a possibilidade de autoria, tornando-se sujeito na produção do conhecimento.

Essa estratégia de valorização do protagonismo e da autoria na produção do conhecimento possibilita/incentiva o professor a buscar na sua prática cotidiana aspectos necessários à sua formação, num movimento que é sempre investigativo, não se limitando aos conhecimentos (re)produzidos no âmbito da EF e, promovendo em suas aulas, dinâmicas que diversifiquem os conteúdos e metodologias. Nesta mesma linha, o estudo de Martins e Freire (2013) destaca a fala de uma professora entrevistada que acredita que uma das maneiras de atrair a participação e envolvimento dos alunos nas aulas é apresentando os objetivos das mesmas a cada encontro e que isso pode provocar debate entre eles sobre os temas e estratégias propostas.

Martins e Freire (2013) afirmam que a competência no trabalho de envolvimento dos alunos nas aulas tem grande importância para ambas as partes (aluno/professor). O fato de permitir que o estudante acompanhe o seu desenvolvimento faz com que ele se torne mais ativo e autônomo. Isso pode aumentar o interesse e participação por todo o processo de ensino aprendizagem e consequentemente fará com que ele se veja valorizado e satisfeito.

Isso também ocorre quando o professor sente a valorização dos alunos com relação às suas aulas e, consequentemente, sente-se mais motivado a continuar construindo práticas inovadoras, no sentido de possibilitar satisfação para ambos no processo ensino-aprendizagem.

No entanto, para além dessas questões relacionadas à motivação e valorização do aluno/professor/ inovação de conteúdos e metodologias de ensino, é preciso que se reflita sobre os objetivos agregados ao Ensino Médio, enquanto a etapa de ensino que antecede a entrada no mercado de trabalho e/ou a preparação para o Ensino Superior.

Para Melo (2013), o professor deve planejar aulas que motivem e incluam todos os jovens, contribuindo, assim, para a formação de cada um deles. Para tanto, a EF precisa considerar que, para além dos conhecimentos da prática, é preciso também abarcar a teoria, para que os alunos e alunas compreendam a real importância da prática de atividades físicas, tanto no 
âmbito escolar como também no seu cotidiano.

A cultura corporal de movimento é muito mais ampla do que as quatro modalidades esportivas apresentadas para os alunos na maioria das escolas, abarcando elementos constitutivos das suas inter-relações teórico-práticas. Os conteúdos da EF contemplam os esportes em geral (coletivos, individuais, de raquete, aquáticos, de aventura etc.), os jogos, a ginástica, a dança/atividades rítmicas e expressivas, as lutas, o circo, além de todas as interrelações que estes conteúdos alcançam com temas como Lazer e Trabalho; Saúde, Organismo Humano; Mídia; Movimentos contemporâneos (SÃO PAULO, 2011). Portanto, existe uma infinidade de conteúdo a serem tratados na $E F$ escolar.

Sampaio e Nascimento (2018) relataram o resultado de uma experiência de tematização do conteúdo "exercício físico e saúde", desenvolvido por integrantes do PIBID em uma escola de educação profissional de Ensino Médio, localizada no município do Crato (CE). O objetivo do estudo foi descrever e analisar uma unidade didática de ensino e a relação ensino-aprendizagem levada a efeito com o conteúdo "exercício físico e saúde". Identificou-se que é possível conduzir um processo de intervenção pedagógica em EF pautada na colaboração, compartilhamento de experiências, criticidade, indissociabilidade entre teoria e prática e noção de movimento humano para além dos aspectos biomecânicos.

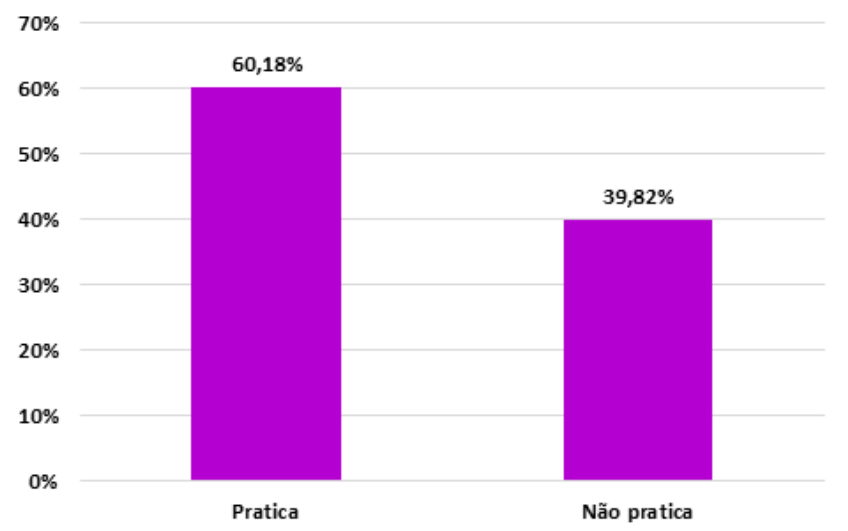

Figura 6. Valores percentuais sobre praticar atividades físicas fora da escola. Fonte: os autores.

Vale ressaltar que a vinculação da EF com a saúde não deve ser restritiva e sim ampliada, uma vez que representa uma das concepções que fundamenta o trabalho da área. Cardoso e Nunez (2014) verificaram em sua pesquisa que os estudantes ao serem questionados sobre quais benefícios a aula de educação física proporciona, constataram um resultado positivo acerca deste dado, visto que $42,1 \%$ dos alunos marcaram a opção saúde e $18,7 \%$ integração. Os autores notaram também que os alunos têm ciência da importância da EF em suas vidas pois, a maioria dos alunos apontam a saúde, a descontração e o bem estar, como benefícios oferecidos pela disciplina. Os autores concluem que as expectativas dos alunos com as aulas de EF no Ensino Médio das escolas de Barra de Garças (MT) vai além do tradicional 'rola bola' e que cabe aos profissionais da área desenvolverem atividades que despertem interesse dos mesmos a fim de que a EF escolar seja vista como uma disciplina importante e rica em conhecimentos e que faça jus à obrigatoriedade da mesma nos componentes curriculares.

Nesse sentido, quando se estabelece uma relação entre os dados apresentados e a prática de atividades físicas fora do ambiente escolar, os resultados apontam dados preocupantes, pois apenas $60,18 \%$ dos alunos realizam alguma atividade física fora da escola (Figura 6).

Um estudo realizado por Pussieldi et al. (2018) buscou verificar o efeito de 20 semanas de EF escolar no nível de atividade física, estado de humor e na qualidade de vida em adolescentes do Ensino Médio. Os resultados do estudo indicam que as aulas contribuíram para a manutenção do nível de atividade física dos alunos.

Acredita-se que este nível de atividade física, tenha sido benéfico na manutenção do estado de humor, visto que, mesmo com o aumento das atividades estressantes no final de semestre como provas e trabalhos, eles não modificaram os aspectos ligados ao estado de humor, apresentando um comportamento estável. Mas houve uma diminuição no domínio psicológico, relação social e meio ambiente da qualidade de vida talvez devido ao fato de que neste período do ano as relações pessoais sejam pioradas em virtude das provas finais (PUSSIELDI et al., 2018, p. 80-81)

Os autores verificaram um destaque entre o perfil das meninas, o grupo não modificou o nível de atividade física, mas houve uma mudança no estado de humor nas variáveis depressão e fadiga, e apresentaram uma diminuição nos domínios: físico, psicológico e relações sociais da qualidade de vida, atribuído provavelmente pelo aumento dos compromissos estudantis. $O$ estudo sugere necessidade de maior incentivo de ações que possam aumentar a participação dos adolescentes em atividades físicas, especialmente no ambiente escolar, sobretudo por meio das aulas de EF (PUSSIELDI et al., 2018).

Segundo Pinto et al. (2015) a atividade física pode ser encarada como fator de proteção para pessoas com doenças crônicas não transmissíveis, tais como esteatose hepática, diabético, obesidade. Assim, seria de extrema importância que os alunos pudessem aprender sobre as inúmeras possibilidades da cultura corporal de movimento para que se engajem em atividades físicas no seu cotidiano a fim de manter uma boa saúde e consequentemente sua qualidade de vida, além de incorporarem esse hábito para diferentes fins (lazer, benefícios psicossociais etc.). Acreditamos ainda que uma EF que contemple diferentes manifestações da cultura corporal de movimento pode promover uma variedade ampla de engajamento em atividades físicas fora do ambiente escolar, melhorando os aspectos da qualidade de vida dos alunos e, em longo prazo, da sociedade em geral.

\section{CONCLUSÃO}

A EF vem enfrentando dificuldades no contexto escolar devido a preferência pelo esporte, falta de empenho dos professores no planejamento, falta de valorização da disciplina, entre outros, e ainda busca consolidar seus conteúdos e objetivos na escola. Dessa forma, o último ciclo da escolarização, o Ensino Médio, tem recebido uma EF repetitiva e pouco voltada à eficiência do ensino da disciplina.

A pesquisa com os alunos e alunas da região da Grande Dourados constatou que o grupo analisado gosta da disciplina de $\mathrm{EF}$, de modo geral os alunos participam das aulas, porém a consideram pouco importante quando comparada com as de- 
mais. Notou-se também, pelas respostas dos alunos, que seus professores não têm apresentado uma variedade de conteúdos da cultura corporal, limitando os conteúdos da EF ao Esporte. Acreditamos que os pontos pesquisados se relacionam entre si, influenciando diretamente um ao outro como um círculo vicioso: os professores não ministram aulas atrativas, os alunos não a consideram relevante para sua vida, os alunos participam apenas para divertimento e obter nota e, portanto, poucos alunos se engajam em atividades físicas fora da escola.

Conclui-se que a EF no Ensino Médio necessita rever seus conteúdos, objetivos, metodologia, a fim de se firmar como uma disciplina que possa oferecer conhecimentos relevantes sobre o corpo e a cultura, para que as aulas tenham significado no dia a dia do aluno. Acreditamos que as discussões sobre a cultura corporal, a atividade física e suas relações com a saúde também são questões que devem ser presentes nos estudos da disciplina com alunos do Ensino Médio, objetivando a disseminação deconhecimentos na busca pela qualidade de vida das pessoas.

\section{REFERÊNCIAS}

ANDRADE, M. M. de. Introdução à metodologia do trabalho científico: elaboração de trabalhos na graduação. 10. ed. São Paulo: Atlas, 2010.

BRACHT, V. A Educação física no ensino fundamental. I Seminário Nacional: Currículo em Movimento - perspectivas atuais, Belo Horizonte, novembro de 2010. Anais eletrônicos... Belo Horizonte, 2010. Disponível em: <http:// portal.mec.gov.br/docman/dezembro-2010-pdf/7170-3-6-educacao-fisica-ensino-fundamental-walter-bracht/file>. Acessado em: 20 de junho de 2015.

BRANDOLIN, F.; KOSLINSKI, M. C.; SOARES, A. J. G. A percepção dos alunos sobre a educação física no ensino médio. Revista da Educação Física, Maringá, v. 26, n. 4, p. 601-10, 2015.

BRASIL. Base Nacional Comum Curricular (BNCC). Educação é a Base Ensino Médio. Brasília, MEC/CONSED/UNDIME, 2018. Disponível em: $<$ http://portal.mec.gov.br/index.php?option=com docman\&view=download\&alias=85121-bncc-ensino-medio\&category slug=abril-2018-pdf\&ltemid=30192>. Acessado em: 02 de dezembro de 2019.

BRASIL. Secretaria de Educação Média e Tecnológica. Parâmetros curriculares nacionais (Ensino Médio) - Linguagens, Código e suas Técnologias. Brasília, DF, 2000. Disponível em: <http://portal.mec.gov.br/seb/arquivos/pdf/ linguagens02.pdf>. Acessado em: 10 de julho de 2018.

CARDOSO, A. G.; NUNEZ, P. R. M. Percepção dos alunos do ensino médio em relação às aulas de educação física. Coleção Pesquisa em Educação Física, Várzea Paulista, v. 13, n. 4, p. 125-32, 2014.

CORDOVIL, A. D. P. R.; GOMES, C. F.; MOREIRA, E. C.; DA SILVA, M. C. R. O espaço da educação física na escola: um estudo sobre os conteúdos das aulas no Ensino Médio. Pensar a Prática, Goiânia, v. 18, n. 4, p. 842-7, 2015.

DAMASCENO, A. L.; DE FREITAS, J. F. F.; LEONARDI, T. J. A motivação na participação dos alunos de 7ㅇ e 90 ano nas aulas de educação física. Horizontes, Dourados, v. 4, n. 8, p. 171-9, 2016.

DARIDO, S. C. A educação física na escola e o processo de formação dos não praticantes de atividade física. Revista Brasileira de Educação física e Esporte, São Paulo, v. 18, n. 1, p. 61-80, 2004.

FARIAS, L. S., W.; DE FREITAS, J. F. F.; IWAMOTO, V.; LEVANDOSKI, G.; LEONARDI, T. J. Educação Física Escolar nos anos finais do Ensino fundamental e a prática de atividades físicas for a da escola. Revista de Educação do Vale do São Francisco, Petrolina, v. 7, n. 12, p. 163-76, 2017

FERREIRA, M. L. dos S.; GRAEBNER, L.; MATIAS, T. S. Percepção de alunos sobre as aulas de educação física no ensino médio. Pensar a Prática, Goiânia, v. 17, n. 3, p. 734-50, 2014

MARTINS, A. B. R.; FREIRE, E. S. O envolvimento dos alunos nas aulas de educação física: um estudo de caso. Pensar a Prática, Goiânia, v. 16, n. 3, p. 760-74, 2013.

MELO, R. F. A evasão escolar nas aulas de educação física no ensino médio. 2013. 21f. Trabalho de Conclusão de Curso (Gradualçao em Educação Física) - Centro Universitário de Brasília, Brasília, 2013.

PINTO, C. G. S.; MAREGA, M.; CARVALHO, J. A. M.; CARMONA, F. G.; LOPES, C. E. F.; CESCHINI, F. L.; BOCALINI, D. S.; FIGUEIRA JUNIOR, A. J. Physical activity as a protective factor for development of non-alcoholic fatty liver in men. Einstein, São Paulo, v. 13, n. 1, p. 34-40, 2015.

PUSSIELDI, G. A.; SILVA, F. J.; PEREIRA, D. A. A. O impacto das aulas de educação física no nível de atividade física, estado de humor e qualidade de vida de adolescentes escolares. Caderno de Educação Física e Esporte, Marechal Cândido Rondon, v. 16, n. 2, p. 73-83, 2018.

RIPARI, R.; BARROS, M. J. A.; FREITAS, J. F. F.; LEONARDI, T. J. Educação física escolar sob o olhar dos alunos do ensino médio. Educación Física y Ciencia, La Plata, v. 20, n. 2, p. e049 (1-12), 2018

SAMPAIO, J. M. F.; NASCIMENTO, P. R. B. Possibilidades didáticas as aulas de Educação Física: o conteúdo "exercício físico e saúde" no ensino médio. Caderno de Educação Física e Esporte, Marechal Cândido Rondon v. 16, n. 2, p. 113-8, 2018.

SANTOS, V. F.; VIEIRA, A. O; MELLO, A. da S.; SCHNEIDER, O.; NETO, A. F.; DOS SANTOS, W. Educação física e o processo de escolarização: uma análise sob a perspectiva do aluno. Revista da Educação Física, Maringá, v. 25, n. 4, p. 539-53, 2014

SÃO PAULO. Secretaria da Educação. Currículo do Estado de São Paulo: Linguagens, códigos e suas tecnologias/Secretaria da Educação. 2. ed. São Paulo: SE, 2011.

SOUZA, F. T. R. de; PAGANI, M. M. A educação física escolar do ensino médio: a ótica do aluno. Revista Educação, Cultura e Sociedade, Sinop, v. 2, n. 2, p. 109-19, 2012.

TEIXEIRA, F. A.; FOLLE, A. Percepção de alunos do ensino fundamental sobre aulas de educação física ministradas por estudantes estagiários. Caderno de Educação Física, Marechal Cândido Rondon, v. 10, n. 18, p. 39-45, 2011.

WANDERLEY JR., E. S.; CEZAR, E. H. A. A educação física como disciplina formadora no ensino médio/técnico: investigando a sua relevância. Caderno de Educação Física e Esporte, Marechal Cândido Rondon, v. 11, n. 2, p. 4959, 2013.

\section{AGRADECIMENTOS}

Os autores agradecem os pais e alunos que concordaram participar da pesquisa e as escolas que fizeram a mediação do contato.

\section{CONFLITO DE INTERESSE}

Os autores do estudo declaram não haver conflito de interesses

\section{FINANCIAMENTO}

Este estudo teve apoio financeiro da Programa Institucional de Bolsas de Iniciação de Científica PIBIC-UFGD.

\section{ORCID E E-MAIL DOS AUTORES}

Crislaine Amelia de Souza

ORCID: 0000-0002-9562-6852.

E-mail: crislaineamelia33@gmail.com

Josiane Fujisawa Filus de Freitas (Autor Correspondente)

ORCID: 0000-0002-0282-7007.

E-mail: josianefffreitas@ufgd.edu.br

Cassia Cristina Furlan

ORCID: 0000-0002-8175-9320.

E-mail: cassiafurlan@ufgd.edu.br 